\title{
Drugs from the Oceans: Marine Natural Products as Leads for Drug Discovery
}

\author{
Karl-Heinz Altmann*
}

\begin{abstract}
The marine environment harbors a vast number of species that are the source of a wide array of structurally diverse bioactive secondary metabolites. At this point in time, roughly $27^{\prime} 000$ marine natural products are known, of which eight are (were) at the origin of seven marketed drugs, mostly for the treatment of cancer. The majority of these drugs and also of drug candidates currently undergoing clinical evaluation (excluding antibody-drug conjugates) are unmodified natural products, but synthetic chemistry has played a central role in the discovery and/or development of all but one of the approved marine-derived drugs. More than 1000 new marine natural products have been isolated per year over the last decade, but the pool of new and unique structures is far from exhausted. To fully leverage the potential offered by the structural diversity of marine-produced secondary metabolites for drug discovery will require their broad assessment for different bioactivities and the productive interplay between new fermentation technologies, synthetic organic chemistry, and medicinal chemistry, in order to secure compound supply and enable lead optimization.
\end{abstract}

Keywords: Clinical development · Drug discovery $\cdot$ Marine natural products $\cdot$ Marine organisms $\cdot$ Medicinal chemistry · Organic synthesis · Semisynthesis

\section{Introduction}

Natural products (NPs) have played a central role in drug discovery and development ever since the first isolation of a NP in pure form, i.e. morphine from opium by Serthürner in 1805 . While the exact numbers vary depending on the type of analysis (including the definition of the term natural product), it is indisputable that NPs are at the origin of a large fraction of our current armamentarium of drug molecules, either as such (i.e. as unmodified NPs) or as lead structures for drug discovery and development..$^{[1-3]}$ In a more indirect way, NPs or (semi)synthetic NP-derivatives can also serve as probes for chemical biology studies, which may then provide new input for drug discovery; prominent examples of this type are the emergence of mTOR as an

${ }^{\star}$ Correspondence: Prof. Dr. K.-H. Altmann ETH Zürich

Department of Chemistry and Applied Biosciences Institute of Pharmaceutical Sciences

Vladimir-Prelog-Wag 4

$\mathrm{HCl} \mathrm{H} 405$

$\mathrm{CH}-8093$ Zurich

E-mail: karl-heinz.altmann@pharma.ethz.ch important current target for new anticancer drugs or the discovery of S1P receptors as a new target family for drug discovery in different disease areas (based on mechanistic studies with the NP rapamycin ${ }^{[4]}$ and the NP-derivative FTY720 (fingolimod), ${ }^{[5]}$ respectively). The possible reasons for the pronounced lead potential of NPs for drug discovery have been discussed in a number of recent review articles ${ }^{[6]}$ and they shall not be reiterated here.

While the majority of NP-derived drugs originate from terrestrial plants, fungi, or microorganisms, NPs isolated from marine organisms are assuming an ever increasing role in the search for new bioactive secondary metabolites. A priori, this is not a surprising development as oceans cover $70 \%$ of the earth's surface and represent $95 \%$ of its biosphere; [7] it has been estimated that the marine environment harbors more than one million species and is home to one billion different kinds of marine microbes. ${ }^{[8]}$ The species diversity offered by the marine environment can be expected to translate into structural diversity at the level of the secondary metabolites produced..${ }^{[9]}$ In fact, it has been argued that compared to their terrestrial counterparts, marine NPs show a higher incidence of significant bioactivity, which is often associated with a high degree of structural novelty. ${ }^{[9,10]}$

Out of the 35 known phyla of the animal kingdom, 34 are represented in the marine environment, with 8 being exclusively aquatic. ${ }^{[7]}$ Thus, the majority of bioactive marine natural products have been isolated from invertebrates $(75 \%$ during the period from 1985 to 2012), with the phyla
Porifera (sponges) and Cnidaria being the most dominant sources by far (accounting for $c a .57 \%$ of the total number of bioactive marine NPs). ${ }^{[11]}$ These organisms are not equipped with any physical means of protection; ${ }^{[12]}$ instead, they release secondary metabolites, e.g. toxins, ${ }^{[13]}$ as a chemical way of defense. ${ }^{[14]}$ It should be noted, however, that many of these compounds are not produced by the apparent source organism itself, but rather originate from or are made in concert with single-celled organisms (dinoflagellates, bacteria, and others), many of which have not been cultured. Thus, the total biomass of a sponge may include up to $35 \%$ of bacterial cells ${ }^{[15]}$ and more than 25 bacterial phyla have been isolated from marine sponges.[16] It has also been noted that $22 \%$ of the 411 NPs known in 2013 to be produced by marine actinomycetes were derived from spongeassociated species. ${ }^{[17]}$

A broad range of biological effects has been described for marine NPs, but the spectrum is clearly dominated by cytotoxic and antiproliferative activities ( $>50 \%$ of all bioactivities reported). ${ }^{[11]}$ While this may indeed reflect the natural function of these compounds as part of the chemical defense machinery of the producing organism (or the host organism harboring the producing species), it may also be caused by a bias in the profiling of marine NPs, which is often limited to the assessment of effects on cancer cell proliferation/survival.

The number of newly isolated marine NPs is steadily increasing and significantly more than 1000 new compounds per year have been isolated regularly since $2008,[18]$ 
bringing the total number of marine natural products to $c a .27^{\prime} 000$ by the end of 2015. ${ }^{19]}$ This increase is fueled by a tremendous number of new marine species that are discovered every year, with advances in diving and submersibles technology enabling sample collections in previously difficult-to-access regions. At the same time, the increased efficiency of genome sequencing provides information on an ever growing number of biosynthetic gene clusters, ${ }^{[20]}$ and improved spectroscopic methods allow for structure elucidation with trace amounts of unknown substances. ${ }^{[21]}$ Notwithstanding these recent advances, the set of organisms that have been scrutinized for bioactive secondary metabolites is still very limited and much remains to be discovered. ${ }^{[18]}$

The intriguing and often unique biological profiles of marine secondary metabolites should make them attractive starting points for drug discovery, but marine NPbased biomedical research is faced with a number of intrinsic obstacles that do not exist for terrestrial NPs (or at least not to the same extent). While adequate material supply for pharmacological profiling and eventual drug development can be a problem for both marine as well as terrestrial NPs, in general, this issue is significantly more pronounced for marine-derived compounds. In many cases, the latter are initially obtained from the natural source in very low quantities and compound supply often cannot be sustained for ecological (and also economic reasons). ${ }^{[22]}$ For marine bacteria, this hurdle has been overcome by large-scale fermentation in individual cases, but this required substantial optimization of fermentation conditions (vide infra). ${ }^{10]}$ On the other hand, more delicate organisms like sponges, are difficult to cultivate; ${ }^{[13]}$ in addition, relevant gene clusters may remain silent under breeding conditions, although this has been resolved by mixed fermentation, in some cases. [10] Apart from biotechnological approaches, the total chemical synthesis of marine NPs in many cases has proven to be a suitable means to generate material for biological interrogation, at least at an early stage of biomedical research.[23] Moreover, while synthetic routes to elaborate carbon scaffolds and/or complex stereochemical arrays often take a long time to establish, chemical synthesis not only allows access to the natural product itself, but it also offers the potential to deliver structures not easily accessible by derivatization or modification of an isolated natural product. ${ }^{[10]}$

At this point in time, seven (types of) drugs have been approved for clinical use that can be confidently traced back to a marine NP (for the purpose of this review, the three FDA-approved products that are based on $\omega 3$ polyunsaturated fatty acids will be considered as one 'drug') and several more are at various stages of clinical development. This short review in a first part summarizes the origin, structure, and clinical uses of the marine-derived drugs that are approved at this point in time and it attempts to highlight some of the key aspects of their discovery and development. In a second part, individual candidate drugs that are currently undergoing clinical development will be discussed. Lastly, a short perspective will be provided on SAR studies on complex marine NPs and the future of marine NP-based drug discovery.

\section{Marine NP-derived Drugs}

The first marine NPs with a clear impact on the development of drugs for human use, if only indirectly, were the arabino-nucleosides spongothymidine and spongouridine (Fig. 1) that were isolated in the early 1950s by Bergman and Feeney from extracts of the sponge Tectitethya crypta. ${ }^{[24,25]}$ Interestingly, it has never been determined if these compounds are in fact produced by the sponge itself or by associated microorganisms, although it was recently shown that other nucleosides that are found in extracts of Tectitethya crypta are of bacterial origin. ${ }^{[26]}$

The discovery of spongothymidine and spongouridine spurred the synthesis and biological evaluation of numerous other nucleosides, eventually leading to the discovery of the anti-leukemia drug cytara- bine (ara-C, arabinosylcytosine) and the antiviral agent vidarabine (ara-A, arabinosyladenine) (Fig. 1). As has been discussed elsewhere, ${ }^{[27]}$ there is a direct line of chemical research that links these drugs to the sponge natural products spongothymidine and spongouridine. Cytarabine was FDA-approved in 1969 and is still in use today for the treatment of acute lymphocytic leukemia (ALL), acute myeloid leukemia (AML), non-Hodgkins lymphoma, and myelodysplastic syndrome (MDS); vidarabine was approved in 1976 for the treatment of Herpes infections, but is no longer in use either in the US or in Europe.

The first FDA-approved drug that was directly derived from a marine NP was the pain medication ziconotide in 2004 (as Prialt $\left.{ }^{\circledR}\right)$. Ziconotide is the synthetic equivalent (manufactured by chemical synthesis but structurally identical with) of the peptide toxin $\omega$-conotoxin MVIIA, which comprises 25 amino acid residues and includes three disulfide bonds (Fig. 2). ${ }^{[28]}$

$\omega$-conotoxin MVIIA is produced by the venomous fish-hunting cone snail Conum magnus as a component of a whole collection of toxins that serve to immobilize prey by targeting different physiological mechanisms in their neuromuscular system. ${ }^{[28]}$ It is a highly specific antagonist of the $\mathrm{N}$-type voltage-gated calcium channel $\mathrm{Ca}_{\mathrm{v}} 2.2$,[29] thus blocking excitatory neurotransmitter release from the primary afferent nerve terminals, which results in antinociception. Ziconotide is indicated for the management of severe and chronic pain in patients who are refractory or intolerant to other pain medications, including opioid analgesics; the drug needs to be administered by intrathecal infusion, which limits the breadth of its application. However, it has been pointed out ${ }^{[30]}$ that apart from its use as a powerful analgesic, the value of ziconotide is also manifest in the identification of $\mathrm{Ca}_{\mathrm{v}} 2.2$ as a target for pain suppression, which can now be pursued with small molecules that may be orally bioavailable.

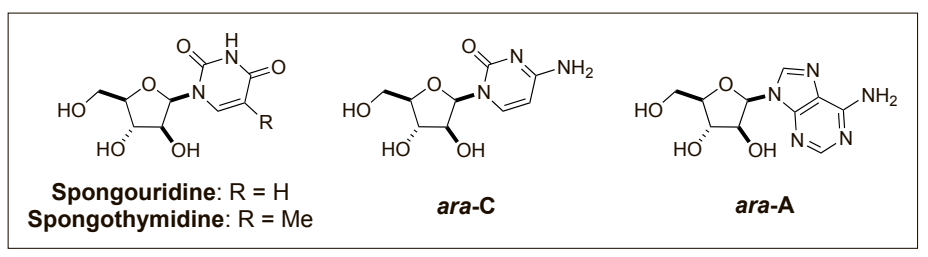

Fig. 1. Molecular structures of the marine NPs spongouridine and spongothymidine and of the derived drugs ara-C and ara-A.

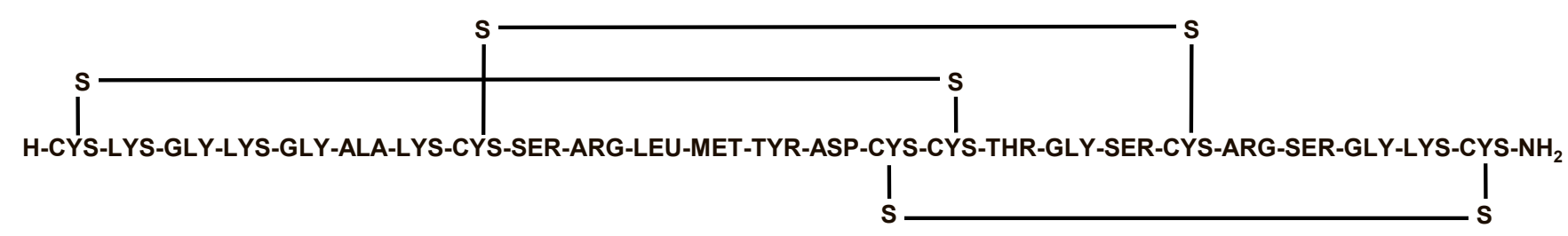

Fig. 2. Amino acid sequence of $\omega$-conotoxin MVIIA (ziconotide) and arrangement of disulfide bonds. 
Like ziconotide, the anticancer drug trabectedin embodies the structure of a NP, in this case the alkaloid ET-743 (Scheme 1). The latter is a member of a larger family of related structures that were first isolated from the Caribbean tunicate Ecteinascidia turbinata in 1990 by Rinehart and coworkers and termed ecteinascidins; ;31] ET-743 was simultaneously also isolated by Wright and co-workers from the same organism. ${ }^{[32]}$

The compound covalently modifies DNA by preferential binding to GC-triplets and subsequent reaction with the guanine amino group at the carbinolamine site, ultimately causing double strand breaks through engagement of the Nucleotide Excision Repair (NER) system. ${ }^{[33]}$ Trabectedin has been approved in Europe since 2007 (as Yondelis ${ }^{\circledR}$ ), for the treatment of soft tissue sarcoma and ovarian cancer; the compound also obtained FDA approval in 2015 as second line treatment of metastatic liposarcoma or leiomyosarcoma.

In contrast to ziconotide, the natural source organism in the case of trabectedin did not yield sufficient quantities of the drug substance in an economically viable process, although aquaculture was used to produce material for part of the clinical studies. ${ }^{[34]}$ The supply problem for trabectedin was ultimately overcome by the development of a semisynthesis route from another natural product, cyanosafracin B, that can be obtained by fermentation of the bacterium Pseudomonas fluorescens. ${ }^{[34]}$ One of the key steps in this semisynthesis is the conversion of T1 into T3 via quinone methide T2 in 58\% overall yield (Scheme $1)$, using conditions that had been developed previously by Corey and co-workers as part of their total synthesis of ET-743. [35] According to ref. [34], trabectedin is obtained from cyanosafracin B in 23 steps and $3 \%$ overall yield.

The complexity of the process for the production of trabectedin is even surpassed by the chemistry associated with the preparation of eribulin, which is a fully synthetic truncated derivative of the marine natural product halichondrin B (Scheme 2). ${ }^{[36]}$ The latter was isolated in 1986 by Hirata and Uemura from the marine sponge Halichondria okadai (together with a number of related structures) and found to exhibit highly potent antitumor activity. ${ }^{[37]}$ Halichondrin B was subsequently demonstrated to be a tubulin polymerization inhibitor and it has generally been assumed that binding of the compound to tubulin occurs at the vinca site. ${ }^{[38]}$ However, while no structural data are available for tubulinbound halichondrin $\mathrm{B}$, it has recently been shown that eribulin binds to a new site on $\beta$-tubulin that does not overlap with the vinca domain. [39]

The discovery of eribulin has its origin in the work of Kishi and colleagues on the total synthesis of halichondrin B and related natural products. ${ }^{[40]}$ Biological evaluation of the halichondrin fragments generated as part of the total synthesis work revealed that the biological activity of halichondrin B was almost exclusively associated with the macrocyclic part of the structure (E1) (Scheme 2). ${ }^{[36]}$ However, while truncated analog E1 was highly potent in vitro, it showed no in vivo antitumor activity. This finding spurred further synthetic work that led to analog $\mathbf{E} 2$ and eventually to eribulin, with the replacement of the bridging lactone oxygen in halichon-

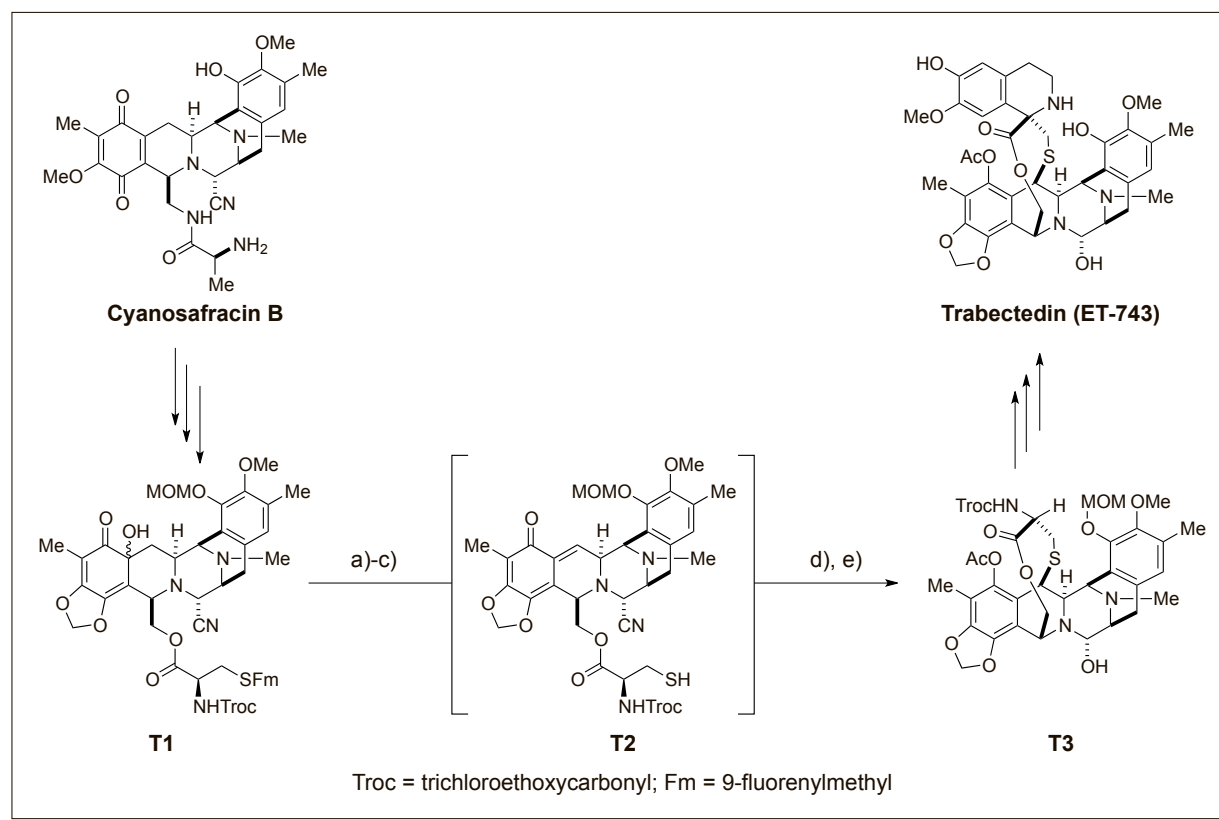

Scheme 1. Molecular structure of trabectedin and one of the key transformations in its semisynthesis from cyanosafracin B. a) DMSO, $\mathrm{Tf}_{2} \mathrm{O}, \mathrm{CH}_{2} \mathrm{Cl}_{2},-40{ }^{\circ} \mathrm{C}$; b) $i-\mathrm{Pr}_{2} \mathrm{NEt}, 0{ }^{\circ} \mathrm{C}$; c) $t-\mathrm{BuOH}, 0{ }^{\circ} \mathrm{C}$; d) $\left.\left(\left(\mathrm{CH}_{3}\right)_{2} \mathrm{~N}\right)_{2} \mathrm{C}=\mathrm{N}-t-\mathrm{Bu} ; \mathrm{e}\right) \mathrm{Ac}_{2} \mathrm{O}, 23^{\circ} \mathrm{C}, 58 \%$. drin $\mathrm{B}$ by a $\mathrm{CH}_{2}$ group in eribulin (i.e. the transformation of a macrolactone into a macroketone) being triggered by the insufficient metabolic stability of $\mathbf{E 2}$ in mouse serum. ${ }^{[36]}$ Eribulin is produced in 62 chemical steps from commercial starting materials; a Nozaki-Hiyama-Kishi reaction at $\mathrm{C} 13-\mathrm{C} 14$ constitutes the ring-closing step. ${ }^{[36]}$ Eribulin mesylate was approved by the FDA in 2010 (as Halaven ${ }^{\circledR}$ ) for the treatment of metastatic breast cancer in patients who previously received at least two chemotherapeutic regimens. While it is not known to this author how much material is manufactured to meet the clinical demand of eribulin, the amount probably does not exceed a few $\mathrm{kg}$ per year.

Notwithstanding the awesome complexity of eribulin, the structurally most complex marine-derived drug is arguably the anticancer drug brentuximab-vedotin. Brentuximab-vedotin is an antibody-drug conjugate (ADC) that is composed of an antibody against the tumor-specific surface antigen CD30, a cathepsin B-cleavable linker moiety (to allow for preferential drug release in tumor cells) and the pentapeptide monomethyl auristatin $\mathrm{E}$ as a cytotoxic drug cargo (Fig. 3). ${ }^{[41]}$ Monomethyl auristatin $\mathrm{E}$ is a synthetic analog of the marine natural product dolastatin 10 (Fig. $3)$; ${ }^{[42]}$ the latter was isolated by Pettit and co-workers from the sea hare Dolabella auricularia and found to be an extremely potent cytotoxic and antitumor agent. ${ }^{[43]}$

Monomethyl auristatin E together with a series of related analogs was first prepared by the Pettit group as part of a more comprehensive SAR study around dolastatin $10^{[42]}$ and later found to be an ideal cargo for ADCs. ${ }^{[41]}$ Like halichondrin B and eribulin, dolastatin 10 and auristatin $\mathrm{E}$ (and also F, vide infra) are inhibitors of tubulin assembly. However, in contrast to eribulin, auristatin $\mathrm{E}$ has been shown in structural studies to bind to the vinca domain on tubulin ${ }^{[44]}$ (as is also the case for dolastatin 10, based on biochemical studies $^{[45]}$ ). Brentuximab vedotin was approved by the FDA in 2011 (as Adcetris ${ }^{\circledR}$ ) for the treatment of patients with Hodgkin lymphoma (after failure of autologous stem cell transplant (ASCT) or after failure of at least two prior multi-agent chemotherapy regimens if patients are not ASCT candidates) or with systemic anaplastic large cell lymphoma (after failure of at least one prior multi-agent chemotherapy regimen). In Europe the drug was approved in 2015.

A special type of marine NP-derived drugs are $\omega 3$ polyunsaturated fatty acids, in the sense that they have much simpler structures than all of the other compounds discussed in this section. In 2004, the FDA approved a mixture of the ethyl esters of fish-derived $\omega 3$ polyunsaturated fatty ac- 


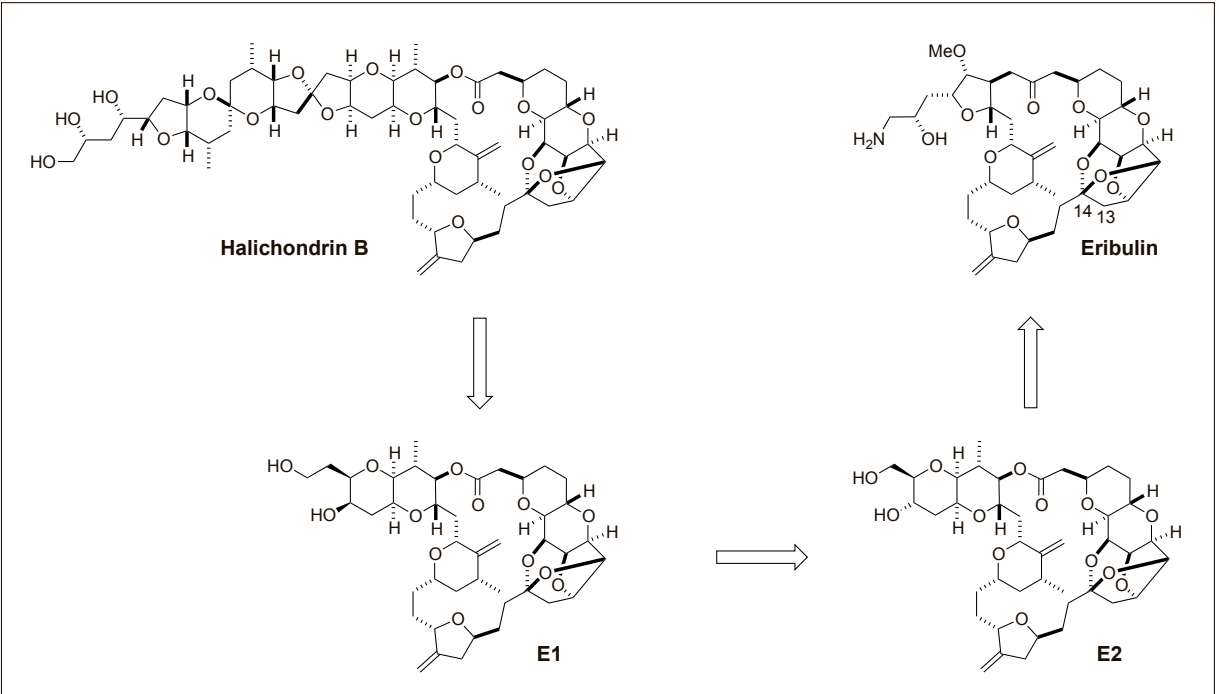

Scheme 2. Molecular structures of halichondrin B and eribulin and of two crucial analog structures on the discovery path from NP to synthetic drug.

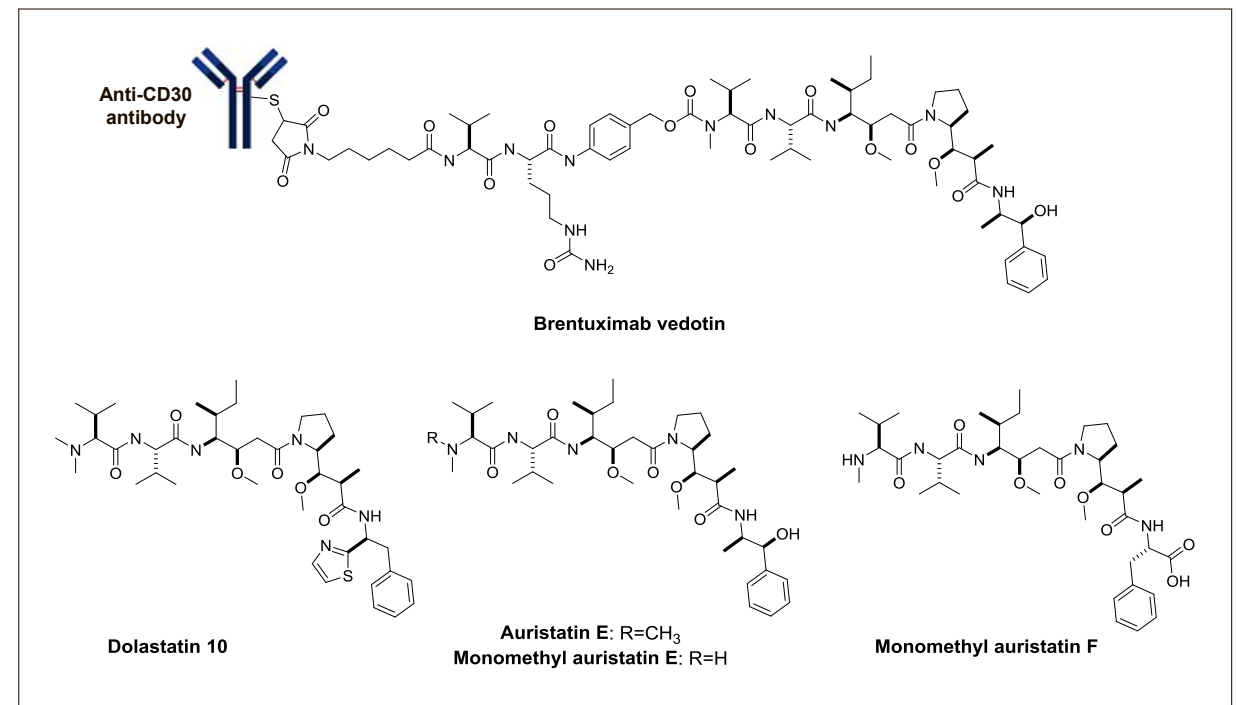

Fig. 3. Molecular structures of the ADC brentuximab vedotin, the natural product dolastatin 10 and the derived synthetic antimitotic agents auristatin $\mathrm{E}$, monomethyl auristatin $\mathrm{E}$, and monomethyl auristatin $\mathrm{F}$.

ids $\left(\right.$ Lovaza $\left.^{\circledR}\right)$, primarily eicosapentaenoic acid (EPA) and docosahexaenoic acid (DHA) (Fig. 4), as an adjunct to diet to reduce triglyceride levels in patients with severe hypertriglyceridemia.

Lovaza $^{\circledR}$ is derived from fish oil obtained from ocean fish families such as Engaulidae, Carangidae, Clupeidae, Osmeridae, Salmonidae, and Scromboidae. The mechanism of action of the drug is not completely understood, but is likely to include inhibition of acyl-CoA:1,2-diacyl- glycerol acyltransferase, increased mitochondrial and peroxisomal $\beta$-oxidation in the liver, and increased plasma lipoprotein lipase activity. ${ }^{[46]}$ In addition, EPA and DHA are poor substrates for the enzymes responsible for triglyceride synthesis and they inhibit esterification of other fatty acids. In the meantime, pure EPA ethyl ester $\left(\right.$ Vascepa $\left.^{\circledR}\right)$ and a mixture of free (fish-derived) $\omega 3$ polyunsaturated acids, consisting primarily of EPA and DHA (Epanova $\left.{ }^{\circledR}\right)$ have been FDA-approved in 2013 and

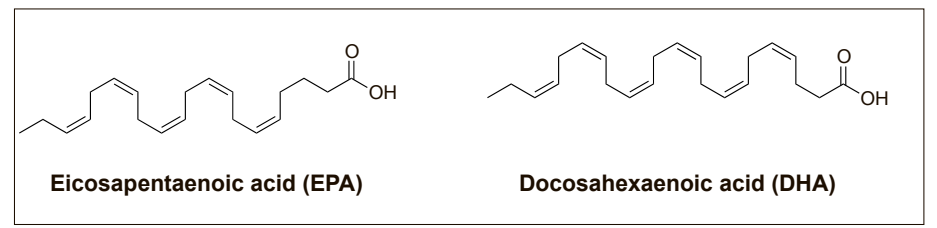

Fig. 4. The major fishderived $\omega 3$ polyunsaturated fatty acids.
2014, respectively, for the same indication as Lovaza ${ }^{\circledR}$.

\section{Marine NP and NP Derivatives in Clinical Development}

It is obviously difficult to assemble a reliable collection of all marine-derived drug candidates currently undergoing clinical development, as this information is fragmented across the literature or may not at all be in the public domain. The following discussion is based on the information available on the website 'Marine Pharmacology'[47] that is maintained by Prof. A. M. S. Meyer, who is a professor of pharmacology at Midwestern University in Chicago, IL, USA. According to this website, 27 marine-derived drug candidates were in clinical development in April 2016; for one of these compounds, ADC ABV833, development has been terminated in the meantime. While this (corrected) number may not be fully accurate at this point in time, at least 26 compounds appear to be undergoing active development or studies are planned (5 in Phase III, 8 in Phase II, and 13 in Phase I). Interestingly, 23 of these 26 compounds are developed for oncology indications and of those 23, 17 are ADCs that are based on two marine NPderivatives only (monomethyl auristatin $\mathrm{E}$ (13 ADCs) and monomethyl auristatin F (4, Fig. 3)). Thus, the structural diversity of the clinical pipeline is more limited than the plain numbers seem to suggest. Of the low-molecular weight compounds, all but two are unmodified NPs (exceptions are the Phase II compounds lurbinectedin, ${ }^{[48]}$ which is an analog of trabectedin, and GTS-21, ${ }^{[49]}$ which is a synthetic derivative of anabaseine) and the majority is prepared by chemical synthesis (based on publicly available information).

It is not the purpose of this review to address each of these drug candidates explicitly, rather only three specific examples shall be highlighted in the following, each of which is distinct by its structure or mode of action (or both).

\subsection{Tetrodotoxin}

Tetrodotoxin (TTX) is a marine alkaloid with a unique pentacyclic structure (Fig. 5). The compound is well known as the (highly) toxic principle of the pufferfish (which is considered a culinary specialty in Japan, but also in other countries). However, TTX is not unique to pufferfish, but has been isolated from at least six phyla of organisms within the Animalia kingdom, thus suggesting that the compound may actually be produced by symbiotic bacteria (including TTX in pufferfish). ${ }^{[50]}$

The compound is an antagonist of voltage-gated sodium channels and its analge- 


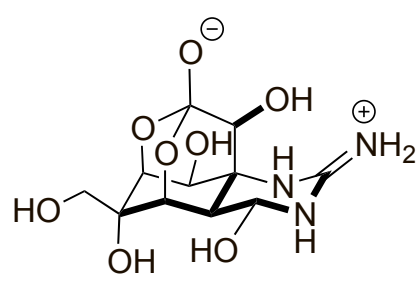

Fig. 5. Three-dimensional structure of the marine toxin tetrodotoxin.

sic effects are related to the inhibition of the initiation and conduction of impulses in the peripheral nervous system. ${ }^{[51]}$ TTX is currently undergoing Phase III clinical trials for severe pain, with material that is extracted from pufferfish livers; administration of the compound can be intramuscular or subcutaneous. ${ }^{[52]}$

\subsection{Aplidine}

Linear and cyclic (depsi)peptides represent an important subgroup of marine NPs that can be equipped with a wide range of biological activities. ${ }^{[53]}$ Aplidine is a cyclic depsipeptide that was originally isolated from the Mediterranean tunicate Aplidium albicans ${ }^{[54]}$ and that is related to the didemnin family of marine NPs that are produced by the Caribbean marine tunicate Trididemnum solidum (Fig. 6).[55] Formally, aplidine is a dehydro analog of didemnin $\mathrm{B}$, which was the first marine NP ever to be advanced to clinical trials in humans, but whose development as an anticancer agent was terminated in Phase II.

Aplidine is a very potent antitumor agent with a complex mode of action, including direct apoptosis-inducing activity, but also effects on the tumor microenvironment. ${ }^{[56]}$ Most recently, it has also been reported to bind to the translation elongation factor eEF1A2. ${ }^{[57]}$ Aplidine is currently undergoing Phase III trials in multiple myeloma in combination with dexamethasone. The drug is produced by chemical synthesis.

\subsection{Salinosporamide $\boldsymbol{A}$}

Salinosporamide A (also known as marizomib and NPI-0052) (Fig. 7) is a halogenated marine NP with an unprecedented structure that was first isolated by Fenical and co-workers in 2003 from the marine bacterium Salinispora tropica. ${ }^{[58]}$

The genus Salinispora comprises obligate marine actinomycetes that are found in ocean sediments and the first members of this genus had been described only shortly before the discovery of salinosporamide A (also by Fenical). ${ }^{[59]}$ Thus, salinosporamide $A$ is a very illustrative example for how the discovery and cultivation of new marine species is intimately related to the discov- ery of new molecular architectures and bioactivities (vide supra). Salinosporamide A is a potent inhibitor of the $20 \mathrm{~S}$ proteasome from different species, including humans, and thus acts on the same molecular target as the approved anticancer drugs bortezomib and carfilzomib.[60] Proteasome inhibition by salinosporamide $\mathrm{A}$ is based on a unique mechanism that first involves lactone opening by the side chain hydroxy group of the active site Thr, followed by intramolecular displacement of chloride by the hydroxy group released from the lactone ring, to form a tetrahydrofuran ring (Fig. 7). Salinosporamide A has completed a number of Phase I studies and is currently undergoing another Phase I and a Phase I/II study in malignant glioma (in the US). Given the fact that the first Phase I trial with the compound started in March of 2006, it is somewhat surprising that it has not been advanced beyond this initial phase of clinical testing. ${ }^{61]}$ Remarkably, the GMP grade material for the clinical trials is manufactured using an optimized bacterial fermentation process that delivers a titer of $450 \mathrm{mg} / \mathrm{L}$ in shake flasks and of $360 \mathrm{mg} / \mathrm{L}$ in a large scale fermenter. ${ }^{[60]}$

\section{Conclusions and Outlook}

In this short review I have highlighted the impact of marine natural products on drug discovery at the levels of marine NPderived marketed drugs and the current clinical development pipeline. While one may be tempted to argue that the number of marine-derived drugs is small, this needs to be compared to the total number of marine NPs known, which is on the order of $27^{\prime} 000 .{ }^{[19]}$ Even if one excludes spongothymidine and spongouridine from the analysis (in light of their only indirect impact on the discovery of ara-C and ara-A), the discovery of five drugs from a pool of only $27^{\prime} 000$ compounds is highly impressive and certainly exceeds the success rates of HTS-based drug discovery. At the same time, it is also true that with the exception of $\omega 3$ polyunsaturated fatty acids all of the marketed drugs (and also candidate drugs) are derived either from a (cyto)toxic (the majority) or a neurotoxic NP. It has been suggested that the past focus of marine NP-based drug discovery on oncological indications at least in the US was caused by the fact that the major funding source for marine-based drug discovery research was the NIH/NCI; ${ }^{[61]}$ it needs to be seen if and how this emphasis will change in the future. I also note that the most recently discovered marine NP that has either led to a drug or even a candidate drug currently in clinical development is salinosporamide A, a compound that was reported already 14 years ago. A general lack of newer NP scaffolds in the development pipeline (i.e. not limited to marine-derived agents) has also been recognized by others. ${ }^{[62]}$

A striking aspect of all successful marine-based drug discovery so far (including the identification of the vast majority of clinical candidates) is a distinct lack of $m e$ dicinal chemistry impact, in terms of the targeted optimization of ADME properties. As pointed out earlier, the majority of marine-derived drugs/candidate drugs that are

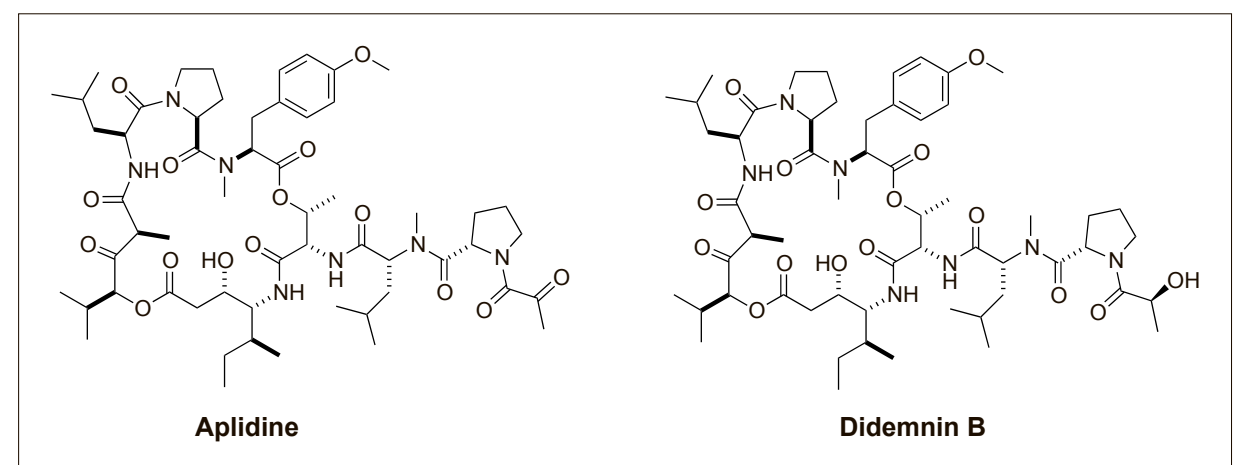

Fig. 6. Marine cyclodepsipeptides aplidine and didemnin B.
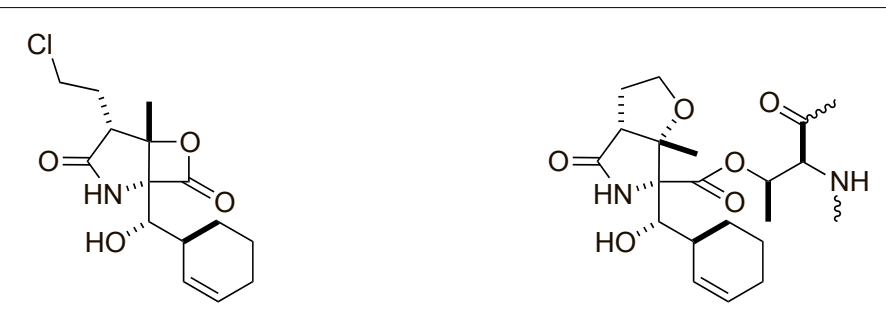

Salinosporamide A
Fig. 7. Structure of salinosporamide A and of the covalent adduct formed with the proteasome after binding and reaction with the active site Thr residue. 
not ADCs are unmodified natural products and for those that are not, it was/is mostly synthetic organic chemistry, rather than medicinal chemistry, that has driven the discovery and development process as the more important enabling chemistry technology. This said, however, it also needs to be noted that comprehensive SAR studies have been conducted on a number of complex marine natural products, including halichondrins, ${ }^{[36]}$ discodermolide, ${ }^{[63]}$ spongistatin, ${ }^{[64]}$ bryostatins, ${ }^{65]}$ migrastatin, ${ }^{666]}$ or apratoxin $S 4,{ }^{67]}$ which have led to the identification of highly potent analogs with significantly simpler structures than the parent natural products (with eribulin as the prime example). Thus, Wender's extensive work on bryostatins has led to the discovery of simplified analogs ( 'bryologs') that may have potential as anti-HIV agents or for the treatment of Alzheimer's disease (reviewed in ref. [65] together with other examples of a 'Function through Synthesis-Informed Design' approach). Likewise, targeted medicinal chemistry work on new eribulin analogs has led to compounds that are no longer susceptible to P-glycoprotein mediated drug efflux ${ }^{[68]}$ and/or are orally bioavailable (up to $20 \%$ vs. $3 \%$ for eribulin). ${ }^{[69]}$

Given the pace of new compound discovery from marine sources and in light of the unfathomable species diversity of the marine environment, it is safe to predict that we will witness the discovery of many new bioactive scaffolds from marine organisms in the years to come. To successfully leverage these basic discoveries for drug discovery research will require the continued development of appropriate fermentation methods for marine organisms (to enable direct development of a marine NP and/or to provide sufficient quantities of material for semisynthesis); at the same time, the power of organic synthesis and medicinal chemistry will have to come to bear on SAR evaluations and lead optimization. From a personal perspective, perhaps most important will be the assessment of marine NPs for as broad a range of bioactivities as possible, in order to ensure the full exploitation of their structural diversity at the biological level.

\section{Acknowledgements}

The help of Simon Glauser and Dr. Bernhard Pfeiffer in editing and proof-reading the manuscript is acknowledged.

Received: July 11, 2017
[1] D. J. Newman, G. M. Cragg, J. Nat. Prod. 2016, 79, 629.

[2] E. Patridge, P. Gareiss, M. S. Kinch, D. Hoyer, Drug Discov. Today 2016, 21, 204.

[3] D. Camp, A. Garavelas, M. Campitelli, J. Nat. Prod. 2015, 78, 1370.

[4] For a recent review, see: D. Benjamin, M. Colombi, C. Moroni, M. N. Hall, Nat. Rev. Drug Discov. 2011, 10, 868.

[5] For a recent review, see: K. Chiba, A. Kunimoto, Fut. Med. Chem. 2012, 4, 771.

[6] For recent reviews see: a) S. Rizzo, H. Waldmann, Chem. Rev. 2014, 114, 4621. b) S. Wetzel, R. S. Bon, K. Kumar, H. Waldmann, Angew. Chem. Int. Ed. 2011, 50, 10800.

[7] N. Fusetani, in 'Progress in Molecular and Subcellular Biology', Eds. N. Fusetani, W. Kem, Berlin, Heidelberg, 2009, 1.

[8] Y. M. Vaske, P. Crews, in 'Bioactive Compounds from Marine Foods: Plant and Animal Sources', Eds. B. Hernández-Ledesma, M. Herrero, Chichester, 2014, 1

[9] C. R. Pye, M. J. Bertin, R. S. Lokeya, W. H. Gerwick, R. G. Linington, Proc. Natl. Acad. Sci. 2017, 114, 5601.

[10] R. Montaser, H. Luesch, Future Med. Chem. 2011, 3, 1475.

[11] Y. Hu, J. Chen, G. Hu, J. Yu, X. Zhu, Y. Lin, S. Chen, J. Yuan, Mar. Drugs 2015, 13, 202.

[12] J. Coll, Chem. Rev. 1992, 92, 613.

[13] F. Flam, Science 1994, 266, 1324.

[14] D. Kelman, Y. Kashman, R. T. Hill, E. Rosenberg, Y. Loya, Pure Appl. Chem. 2009, 81,1113

[15] U. Hentschel, J. Piel, S. M. Degnan, M. W. Taylor, Nat. Rev. Microbiol. 2012, 10, 641.

[16] M. W. Taylor, R. Radax, D. Steger, M. Wagner, Microbiol. Mol. Biol. Rev. 2007, 71, 295.

[17] U. R. Abdelmohsen, K. Bayer, U. Hentschel, Nat. Prod. Rep. 2014, 31, 381.

[18] a) J. W. Blunt, B. R. Copp, R. A. Keyzers, M. H. G. Munro, M. R. Prinsep, Nat. Prod. Rep. 2017, 34, 235; b) J. W. Blunt, B. R. Copp, R. A. Keyzers, M. H. Munro, M. R. Prinsep, Nat. Prod. Rep. 2016, 33, 382; c) J. W. Blunt, B. R. Copp, R. A. Keyzers, M. H. G. Munro, M. R. Prinsep, Nat. Prod. Rep. 2015, 32, 116; d) J. W. Blunt, B. R. Copp, R. A. Keyzers, M. H. G. Munro, M. R. Prinsep, Nat. Prod. Rep. 2014, 31, 160; e) J. W. Blunt, B. R. Copp, R. A. Keyzers, M. H. G. Munro, M. R. Prinsep, Nat. Prod. Rep. 2013, 30 , 237; f) J. W. Blunt, B. R. Copp, R. A. Keyzers, M. H. G. Munro, M. R. Prinsep, Nat. Prod. Rep. 2012, 29, 144; g) J. W. Blunt, B. R. Copp, R. A. Keyzers, M. H. G. Munro, M. R. Prinsep, Nat. Prod. Rep. 2011, 28, 196; h) J. W. Blunt, B. R. Copp, M. H. G. Munro, P. T. Northcote, M. R. Prinsep, Nat. Prod. Rep. 2010, 27, 165; i) J. W. Blunt, B. R. Copp, M. H. G. Munro, P. T. Northcote, M. R. Prinsep, Nat. Prod. Rep. 2009, 26, 170.

[19] A number of 22000 known marine NP has been quoted for 2011 in ref. [20]. In the period between 2012 and $2015 \mathrm{ca} .5000$ new marine NP have been reported. ${ }^{[18]}$

[20] W. H. Gerwick, B. S. Moore, Chem. Biol. 2012 , 19,85 .

[21] G. E. Martin, eMagRes. 2012, 1, 883.

[22] T. F. Molinski, D. S. Dalisay, S. L. Lievens, J. P. Saludes, Nature Rev. Drug Discov. 2009, 8, 69.

[23] I. Paterson, E. A. Anderson, Science 2005, 310, 451.

[24] W. Bergmann, R. J. Feeney, J. Org. Chem. 1951, 16,981 .

[25] W. Bergmann, R. J. Feeney, J. Org. Chem. 1955, 20, 1501

[26] J. Bertin, S. L. Schwartz, J. Lee, A. Korobeynikov, P. C. Dorrestein, L. Gerwick, W. H. Gerwick, J. Nat. Prod. 2015, 78, 493.

[27] D. J. Newman, G. M. Cragg, K. M. Snader, Nat. Prod. Rep. 2000, 17, 215.

[28] B. M. Olivera, W. R. Gray, R. Zeikus, J. M.
McIntosh, J. Varga, J. Rivier, V. de Santos, L. J. Cruz, Science 1985, 230, 1338.

[29] For a review, see: G. P. Miljanich, Curr. Med. Chem. 2004, 11, 3029.

[30] R. W. Teichert, B. M. Olivera, J. M. McIntosh, G. Bulaj, M. P. Horvath, in 'Venoms to Drugs: Venom as a Source for the Development of Human Therapeutics', Ed. G. F. King, London, 2015, 163.

[31] K. L. Rinehart, T. G. Holt, N. L. Fregeau, J. G. Stroh, P. A. Keifer, F. Sun, L. H. Li, D. G. Martin, J. Org. Chem. 1990, 55, 4513.

[32] A. E. Wright, D. A. Forleo, P. G. Gunawardana, S. P. Gunasekera, F. E. Koehn, O. J. McConnell, J. Org. Chem. 1990, $55,4508$.

[33] For a recent review on the mechanism(s) of action of trabectedin see: M. D'Incalci, N. Badri, C. M. Galmarini, P. Allavena, Br. J. Cancer 2014, 111, 646.

[34] C. Cuevas, A. Francesch, Nat. Prod. Rep. 2009, 26, 322 .

[35] E. J. Corey, D. Y. Gin, R. S. Kania, J. Am. Chem Soc. 1996, 118, 9202.

[36] For a review on the discovery of eribulin, see: $M$ Yu, W. Zheng, B. M. Seletsky, B. A. Littlefield, Y. Kishi, Ann. Rep. Med. Chem. 2011, 46, 227.

[37] Y. Hirata, D. Uemura, Pure Appl. Chem. 1986 $58,701$.

[38] R. Bai, K. D. Paull, C. L. Herald, L. Malspeis, G. R. Pettit, E. Hamel, J. Biol. Chem. 1991, 266 , 15882.

[39] A. E. Prota, K. Bargsten, J. F. Díaz, M. Marsh, C. Cuevas, M. Liniger, C. Neuhaus, J. M. Andreu, K.-H. Altmann, M. O. Steinmetz, Proc. Natl. Acad. Sci. USA 2014, 111, 13817.

[40] For a review on the chemistry of halichondrins, see: K. L. Jackson, J. A. Henderson, A. J. Phillips, Chem. Rev. 2009, 109, 3044.

[41] For a review on the discovery and development of brentuximab vedotin, see: P. D. Senter, E. L. Sievers, Nat. Biotechnol. 2012, 30, 631.

[42] G. R. Pettit, J. K. Srirangam, J. Barkoczy, M. D. Williams, M. R. Boyd, M. E. Hamel, R. K Pettit, F. Hogan, R. Bai, J.-C. Chapuis, S. C. McAllister, J. M. Schmidt, Anti-Cancer Drug Des. 1998, 13, 243.

[43] G. R. Pettit, Y. Kamano, C. L. Herald, A. A. Tuinman, F. E. Boettner, H. Kizu, J. M. Schmidt, L. Baczynskyj, K. B. Tomer, R. J. Bontems, $J$. Am. Chem. Soc. 1987, 109, 6883 .

[44] A. B. Waight, K. Bargsten, S. Doronina, M. O. Steinmetz, D. Sussman, A. E. Prota, PLoS One 2016, 11, e0160890/1.

[45] R. Bai, G. R. Pettit, E. Hamel, Biochem. Pharmacol. 1990, 39, 1941.

[46] This information is taken from the FDA label for Lovaza ${ }^{\circledR}$.

[47] http://marinepharmacology.midwestern.edu/ Accessed on June 25, 2017.

[48] L. Paz-Ares, M. Forster, V. Boni, S Szyldergemajn, J. Corral, S. Turnbull, A. Cubillo, C. F. Teruel, I. L. Calderero, M. Siguero, P. Bohan, E. Calvo, Invest. New Drugs 2017, 35, 198.

[49] C. Beinat, S. D. Banister, M. Herrera, V. Law, M. Kassiou, CNS Drugs 2015, 29, 529.

[50] For a review on the distribution and biosynthetic origin of TTX, see: R. Chau, J. A. Kalaitzis, B. A. Neilan, Aqu. Toxicol. 2011, 104, 61 .

[51] F. R. Nieto, E. J. Cobos, M. Á. Tejada, C. Sánchez-Fernández, R. González-Cano, C. M. Cendán, Mar. Drugs 2012, 10, 281.

[52] N. A. Hagen, L. Cantin, J. Constant, T. Haller, G. Blaise, M. Ong-Lam, P. du Souich, W. Korz, B. Lapointe, Pain Res. Manag. 2017, 1.

[53] For a recent review on marine bioactive peptides, see: R. C. F. Cheung, T. B. Ng, J. H. Wong, Mar. Drugs 2015, 13, 4006.

[54] K. L. Rinehart, A. M. Lithgow-Bertelloni, PCT Int. Pat. Appl. WO 91.04985, Apr. 18, 1991; GB Appl. 89/22,026, Sept. 29, 1989; Chem Abstr. 1991, 115, 248086q. 
[55] For reviews on didemnins, see: a) M. D. Vera, M. M. Joullie, Med. Res. Rev. 2002, 22, 102; b) J. Lee, J. N. Currano, P. J. Carroll, M. M. Joullie, Nat. Prod. Rep. 2012, 29, 404.

[56] C. M. Galmarini, M. D'Incalci, P. Allavena, Mar. Drugs 2014, 12, 719.

[57] A. Losada, M. J. Muñoz-Alonso, C. García, P. A. Sánchez-Murcía, J. F. Martínez-Leal, J. M. Dominguez, M. P. Lillo, F. Gago, C. M. Galmarini, Sci. Rep. 2016, 6, 35100.

[58] R. H. Feling, G. O. Buchanan, T. J. Mincer, C. A. Kauffman, P. R. Jensen, W. Fenical, Angew. Chem. Int. Ed. 2003, 42, 355.

[59] T. J. Mincer, P. R. Jensen, C. A. Kauffman, W. Fenical, Appl. Environ. Microbiol. 2002, 68, 5005.

[60] For reviews on the discovery and development of salinosporamide A, see: a) W. Fenical, P. R. Jensen, M. A. Palladino, K. S. Lam, G. K. Lloyd, B. C. Potts, Bioorg. Med. Chem. 2009,
17, 2175; b) B. C. Potts, K. S. Lam, Mar. Drugs 2010, 8,835 ; c) T. A. M. Gulder, B. S. Moore, Angew. Chem. Int. Ed. 2010, 49, 9346.

61] The protracted development of the compound maybe related to the demise of the company Nereus, which sponsored the early trials with salinosporamide A. See D. J. Newman, G. M. Cragg, Planta Med. 2016, 82, 775.

[62] M. Butler, A. A. B. Robertson, M. A. Cooper, Nat. Prod. Rep. 2014, 31, 1612.

[63] A. B. Smith, III, B. S. Freeze, Tetrahedron 2008, 64, 261

[64] A. B. Smith, III, C. A. Risatti, O. Atasoylu, C. S. Bennett, J. Liu, H. Cheng, K. TenDyke, Q. Xu, J. Am. Chem. Soc. 2011, 133, 14042.

[65] P. A. Wender, R. V. Quiroz, M. C. Stevens, Acc. Chem. Res. 2015, 48, 752 .

[66] For a review, see: E. Giralt, D. Lo Re, Molecules 2017, 22, 198.
[67] Q.-Y. Chen, Y. Liu, W. Cai, H. Luesch, J. Med. Chem. 2014, 57, 3011.

[68] S. Narayan, E. M. Carlson, H. Cheng, H. Du, Y. Hu, Y. Jiang, B. M. Lewis, P. Saxton, B. M Seletsky, K. Tendyke, H. Zhang, W. Zheng, B. A. Littlefield, M. J. Towle, M. J. Yu, Bioorg. Med. Chem. Lett. 2011, 21, 1630.

[69] S. Narayan, E. M. Carlson, H. Cheng, K. Condon, H. Du, S. Eckley, Y. Hu, Y. Jiang, V. Kumar, B. M. Lewis, P. Saxton, E. Schuck, B. M. Seletsky, K. Tendyke, H. Zhang, W. Zheng, B. A. Littlefield, M. J. Towle, M. J. Yu, Bioorg. Med. Chem. Lett. 2011, 21, 1634 